\title{
A RECEPÇÃO DE AGAMÊMNON NAS TERRAS DA RAINHA \\ as versoes de Browning, Rattigan, Asquith e Figgis
}

\author{
Maria Cecília de Miranda Nogueira Coelho* \\ Universidade de São Paulo
}

\begin{abstract}
"Modernos de fato", refletiu ele [Aldous Huxley] "são os Browning". O amor é a nova invenção, e nenhum casal de criaturas humanas foi tão longe, mesmo nos domínios da fábula como Elizabeth Barrett e Robert Browning, cujo grande e inalterável sentimento tem, pelas circunstâncias e vicissitudes em que se formou e cresceu, a beleza cíclica e indestrutível dos mitos.
\end{abstract}

Manuel Bandeira, Elizabeth Barrett Browning

RES U M O

Neste artigo são analisados aspectos da peça de Terence Rattigan The Browning Version, de 1948, cujo título faz referência à famosa tradução inglesa da tragédia Agamêmnon, feita por Robert Browning, em 1877. Analiso também os dois filmes homônimos, The Browning Version (Nunca te amei), dirigidos por Anthony Asquith, em 1951, e por Mike Figgis, em 1994, ambos baseados na peça de Rattigan.

\section{PALAVRAS - CHAVE}

Tragédia grega, The Browning version, cinema

$E_{m} 8$ de Setembro de 1948, estreou no Teatro Phoenix, em Londres, The Browning Version, de Terence Rattigan (1911-1977), dramaturgo conhecido pelo público inglês desde os anos 1930. Quanto à importância dessa obra para seu autor, Dan Rebellato, na introdução da edição dessa peça, conta que Rattigan afirmou que se tivesse de justificar diante de um júri celeste a escolha da profissão de dramaturgo, encenaria The Browning Version. ${ }^{1}$ Como também é informado, o argumento foi inspirado em episódios da vida escolar de Rattigan na célebre escola Harrow, na qual ele foi aluno do professor de línguas clássicas J. W. Coke-Norris. Superando a abordagem do rígido acadêmico, para

\footnotetext{
*deltos@gmail.com

${ }^{1}$ RATTIGAN. The Browning Version, p. xxv.
} 
quem a peça Agamêmnon era um texto para se falar das construções gramaticais mais que da experiência teatral, foi justamente após a leitura da tradução dessa tragédia que Rattigan decidiu tornar-se dramaturgo. ${ }^{2}$ Posteriormente, em 1934, quando deixou o Trinity College, em Oxford, para dedicar-se inteiramente à vida de escritor, Rattigan consolidou uma bem-sucedida carreira, mas com o surgimento de uma nova geração no final dos anos 1950 (capitaneada por John Osborne e Harold Pinter) o estilo Rattigan começou a sair de cena. ${ }^{3}$ No entanto, desde os anos 1990, Rattigan tem voltado à luz. Índice desta redescoberta são as duas recentes versões cinematográficas baseadas em duas de suas peças (The Browning Version e The Winslow Boy, ambas vencedoras do prêmio Ellen Terry Best Play, quando lançadas), dirigidas por Mike Figgis, em 1994, e David Mamet, em 1999, respectivamente.

The Browning Version trata, aparentemente, de uma história cotidiana, na qual o protagonista, Andrew Crocker-Harris, é um rígido e amargurado professor de grego e latim, que está deixando a escola de elite onde lecionou por 18 anos para trabalhar em uma escola de menor importância, devido a problemas de saúde. Além de lidar com a antipatia dos alunos, que o apelidaram de "Crock" (decrépito), a desconsideração dos membros do conselho da escola, que lhe negam uma pensão, e, em particular, do diretor, que o chama de "Himmler" (comandante da SS), Andrew tem, no âmbito privado, de tolerar a presença hostil da esposa, que o trai com um colega seu, professor de ciências. Se estes são elementos de um enredo que pode retratar a vida de muitos homens, o modo como a história foi construída e os personagens delineados a tornam mais complexa. $\mathrm{Na}$ verdade, a peça é uma sofisticada releitura da mais famosa obra de Ésquilo, Agamêmnon, transposta para o século XX. O nome Browning se refere ao escritor inglês Robert Browning, famoso não apenas por seus dotes como poeta, dramaturgo e tradutor de Ésquilo, mas também por sua história de amor e casamento com a poeta Elizabeth Barrett, em união singular que ficou no imaginário não somente do povo inglês, mas que, atravessando mares, veio a ser objeto de louvor nas palavras de Manuel Bandeira, como vimos pela epígrafe deste artigo, excerto de uma crônica sobre Elizabeth publicada em 1931 na revista Bazar. ${ }^{4}$

O contexto da epígrafe é o comentário de Bandeira ao lançamento do livro de Dormer Creson (pseudônimo de Dorothy Julia Baynes), Andromeda in Wimpole Street, em que Elisabeth é comparada à lendária jovem acorrentada a um rochedo por seu pai, como vítima sacrificial, e libertada por Perseu. Educada em casa, Elizabeth, por um lado, vivia reclusa com seus 11 irmãos mais novos sob a tirania de um pai ciumento e dominador que a proibira de se casar; por outro, sob seu estímulo, escrevia muito e teve uma

\footnotetext{
${ }^{2}$ DARLOW; HODSON, Terence Rattigan: The Man and his Work, p. 155. Há autores que estabelecem várias comparações entre a vida pessoal de Rattigan e o conteúdo de sua obra; não tenho intenção de tratar desta peça nesta perspectiva.

${ }^{3}$ Indicativo deste estilo é a frase de Rattigan em entrevista dos anos sessenta: "a play isn't well made if you think about how well made it is, if you see the wheels turning" (Introdução de Rebellato, RATTIGAN. The Browning Version, $\mathrm{p}$. xx) e um eco desta postura pode ser visto na peça pelo papel que tem nela e nos filmes o epigrama Scientia est celare scientiam análogo ao epigrama Ars est celare artem. ${ }^{4}$ BANDEIRA. Crônicas da Província do Brasil, p. 224-229.
} 
educação esmerada. Na adolescência lia os clássicos gregos, latinos e italianos no original e também os textos sagrados hebraicos; aos 14 anos havia escrito um poema épico e aos 26 traduziu Prometeu acorrentado. Seus poemas publicados em 1844 chamaram a atenção de Browning, que a visitou em um período no qual fora afetada por uma doença que a deixara por alguns anos praticamente imóvel. Após um casamento secreto, em 1845, seguiu-se a viagem do casal para a Itália, onde, apesar de deserdada pelo pai, viveu por quinze anos um conto de fadas, até 1861, quando faleceu aos 55 anos, deixando Robert e um filho. Ao voltar para Inglaterra, Robert Browning publicou várias obras, entre as quais The Ring and the Book (1869), hino de 21.000 versos dedicados a Elizabeth, e a tradução da peça Agamêmnon (1877). Em 1881 foi criada a Browning Society, o que indica o prestígio dos dois poetas. A história do casal foi levada ao cinema duas vezes pelo mesmo diretor, Sidney Franklin, que por sua vez adaptou a peça mais famosa de Rudolf Besier, The Barretts of Wimpole Street, em filmes de 1934 e 1957, com Charles Laughton e John Gielgud, respectivamente, fazendo o papel do enérgico pai de Elizabeth. Podemos ver, então, que o nome Browning é extremamente significativo, remetendo a um conjunto de fatos, pessoas e obras muito importantes da cultura inglesa no século XIX e início do XX. Ao que parece, a versão de Browning não foi feita para ser usada como texto a ser encenado - diga-se, de passagem, era uma época em que dramas gregos eram encenados no original, e, segundo Prins, Browning foi um dos espectadores que, em 1880, assistiu a uma famosa encenação de Agamêmnon feita por alunos de Oxford. Quanto à tradução de Agamêmnon, como informam Prins e Taplin, em comentários muito breves, o objetivo de Browning de tornar totalmente presente a peça de Ésquilo, fazendo o que ele mesmo chamou de "transcription," produziu, por uma fidelidade literal à língua grega, um texto "tão ilegível" que foi dito: "It's a good thing that the Aeschylus is there to explain what the Browning is meant to mean!".

Nesse contexto, a relação entre os três textos (de Ésquilo, Browning e Rattigan) e dois filmes permite-nos indicar elementos da assimilação da tradição clássica grega pela literatura dramática contemporânea e cinema e compreender o significado de alterações no enredo e caracterização de personagens. Mais particularmente, a peça de Rattigan e os dois filmes nela baseados são obras muito instigantes ao mostrar a interface entre o dramático e o trágico, bem como entre o contexto cultural e acadêmico inglês e a recepção de obras artísticas clássicas, pois a peça foi adaptada mais de uma dezena de vezes para a TV. ${ }^{6}$ Rattigan é também o autor do roteiro do filme de 1951, cujo título em português, Nunca te amei (dado também ao filme de 1994), não é apropriado para traduzir The Browning Version, porque, por um lado, perdemos as referências à peça e ao poeta-tradutor, bem como ao nome do casal inglês, quase mítico, como diz Bandeira, que por sua vez remete a um mítico casal infeliz: Agamêmnon e Clitemnestra. Por outro

\footnotetext{
${ }^{5}$ PRINS. OTOTOTOI: Virginia Woolf and the Naked Cry of Cassandra, p. 166 e TAPLIN. The Harrison Version, p. 245. Para uma análise dos argumentos de Browning em defesa de seus procedimentos como tradutor, veja BENITEZ. On Literal Translation: Robert Browning and the Agamemnon. Os artigos de Prins e Taplin não se detêm na análise da versão de Browning, tratando, respectivamente, da influência de Agamêmnon nas obras de Virginia Woolf e, mais recentemente, da de Tony Harrison (que traduziu a Orestéia, encenada por Peter Hall em 1981).
}

${ }^{6}$ Na TV britânica, Andrew já foi vivido por Peter Cushing (1955), John Gielgud (1959) e Ian Holm (1989). 
lado, o título em português induz o espectador a uma visão unilateral das personagens, em particular da mulher do professor Crocker-Harris, Millie. Curiosamente, apesar de premiados e exibidos na TV a cabo e disponíveis em DVD, são filmes pouco conhecidos do público e, em particular, dos helenistas. Não há nenhuma referência a eles em obras como o recente Agamemnon in Performance, 458 B.C. to A.D. 2004, no qual há, por exemplo, um artigo comentando o filme Appunti per un'Orestiade africana, de Pasolini, e onde também estão os textos de Taplin e Prins.

O primeiro filme, dirigido pelo destacado Anthony Asquith (que em 1925 fundou um cineclube com Bernard Shaw e H.G. Wells), recebeu prêmios importantes e ainda hoje é elogiado, não tendo perdido seu valor e beleza, e reúne grandes nomes como Rattigan, Asquith e Michael Redgrave. ${ }^{7}$ The Browning Version rendeu o prêmio de melhor ator para Redgrave e melhor roteiro para Rattigan, no Festival de Cannes de 1951; melhor filme para Asquith, no Festival de Berlin; e Prêmio Bodil de melhor filme Europeu, e duas indicações ao BAFTA (British Academy of Film and Television Arts), nas categorias de melhor filme e melhor filme britânico. O segundo filme, mesmo não alcançando prêmios importantes como o primeiro, foi indicado para a Palma de Ouro em Cannes, melhor ator para Finney na Boston Society of Film Critics Awards em 1994 e, em 1995, foi indicado para melhor roteiro na premiação pelo BAFTA. Ambos os filmes fazem modificações significativas em relação à peça. Naturalmente, mais importante que exigir fidelidade, é observar o sentido destas modificações e suas consequências na estrutura dramática. Não farei, neste artigo, comparações exaustivas, entre as cinco obras, pois sendo meu objetivo o de estabelecer conexões entre os três textos e os dois filmes, não há espaço para maior detalhamento. ${ }^{8}$

Como a tragédia Agamêmnon, a peça The Browning Version possui sete personagens: Andrew Crocker-Harris, professor de grego e latim; sua esposa Millie; John Taplow, aluno de Andrew; Frank Hunter, professor de ciências e amante de Millie; Dr. Frobisher, diretor da escola, Peter Gilbert, professor que substituirá Andrew, e sua esposa Mrs. Gilbert. Se a homologia com os personagens de Ésquilo - Agamêmnon, Clitemnestra, Cassandra, Egisto, o Vigia; o Arauto e o Coro - não é completa e evidente, ela não deixa de existir parcialmente de maneira significativa. $O$ pequeno número de personagens nesta peça de um ato propicia, também pela unidade de tempo e espaço (toda a peça se passa em pouco mais de uma hora, na sala da casa dos Crocker-Harris), que nos concentremos na observação dos acontecimentos em torno de Andrew. Esse é um nome interessante para o protagonista, devido a sua origem grega (anér) e sua conexão com a palavra andreía, uma virtude tipicamente masculina que o velho professor terá de demonstrar para recuperar sua imagem esfacelada pelos conflitos privados com uma esposa que se tornou vingativa e amarga. Aqui o contexto de uma guerra pública é realçado precipuamente

\footnotetext{
${ }^{7}$ A intensa cooperação no cinema entre Asquith e Rattigan (como roteirista) começou com a adaptação da primeira peça de Rattigan, French without Tears, levada à tela em 1939, após sua estreia em 1936. Rattigan possuía bastante interesse em cinema e com os irmãos Anatole e Dimitri de Grunwald criou sua própria produtora, a International Screenplays, após trabalhar para os estúdios ingleses da Warner Bros.

${ }^{8}$ Tampouco discutirei questões teóricas sobre a relação entre cinema e estudos clássicos. Sobre este tema, veja, por exemplo, COELHO. Helena de Tróia no cinema: metamorfoses do mito, p. 131-159 e GOLDER. "Geek" Tragedy? - Or, Why I'd Rather go to the Movies, p. 175-209.
} 
no âmbito privado, condensando na casa do professor os contextos público e privado da tragédia grega. Taplow tem, ao mesmo tempo, o papel do vigia, observando e comentando os problemas e a amargura de Andrew no ambiente difícil da escola, e de Orestes (uma contaminação das segunda e terceira peças da trilogia esquiliana, certamente), ajudando o seu mestre e "mentor espiritual" a resgatar seu respeito e valor, junto à comunidade. Por outro lado, Hunter, ao mesmo tempo que atua como Egisto, divide com Taplow este papel do vigia, identificando, a partir de certo momento na peça, a desordem instaurada principalmente naquela casa (e no casal) devido ao caráter e comportamento inadequado de Millie. Frobisher e o casal Gilbert teriam, por sua vez, papéis análogos ao do arauto e/ou coro. Versos da tragédia Agamêmnon e referências a esta peça e a sua tradução por Browning servem tanto para mostrar a releitura feita por Rattigan, como para criar redes significativas com passagens em que a alusão ao enredo e personagens da tragédia grega não é explícita. ${ }^{9}$

No diálogo inicial da peça entre Frank e Taplow, que aguarda a chegada de Andrew para um atendimento de tutoria, o jovem reclama de ter de estudar Ésquilo, não porque seja um texto ruim, mas pelo modo como é ensinado:

I don't think the play is muck - exactly. I suppose, in a way, it's rather a good plot, really, a wife murdering her husband and having a lover and all that. I only meant the way it's taught to us - just a lot of Greek words strung together and fifty lines if you get them wrong. ${ }^{10}$

Após imitar o estilo de Andrew e dizer "the man's barely human”, Taplow afirma que, pior do que um sádico, que ainda tem sentimentos, Andrew parece imune às demonstrações de afeto. Voltando a imitar Andrew, Taplow não percebe a entrada da esposa do professor. A cena termina com a saída de Taplow, que, a pedido de Millie, vai à farmácia buscar o medicamento de Andrew, um modo de ela ficar sozinha com Frank. Esta cena não apenas indica que são amantes e que a relação deles já começa a ser problemática, mas, principalmente, que Andrew "não foi sempre o Crock". ${ }^{11}$ Se, por um lado, Millie acha desolador pensar no que suas vidas se transformaram, por outro, tal afirmação, associada àquela feita posteriormente por Andrew, de que tanto ele como ela são dignos de piedade por viverem "two kinds of love.... Worlds apart, as I now know"12 mostra como, neste aspecto, o trágico se transforma em dramático (e também que a tradução do título em português, como Nunca te amei é inadequada).

Quando Taplow retorna, Millie sai para preparar o jantar e tem início uma cena muito interessante na qual Taplow começa a traduzir a partir do verso 1372 do Agamêmnon. Andrew faz algumas correções menores, mas no momento em que Taplow traduz o verso 1400 (uma fala do coro) "Utter such a boastful speech - over - (in a sudden rush of inspiration) the bloody corpse of the husband you have slain" Crock se espanta com a ousadia do aluno. Vale a pena citar o diálogo, que, aliás, é mantido quase inalterado nos dois filmes:

\footnotetext{
${ }^{9}$ Esta releitura dos clássicos gregos não é isolada. Em 1949 Rattigan levou ao palco os dilemas emocionais de Alexandre, o Grande, na peça Adventure Story.

${ }^{10}$ RATTIGAN. The Browning Version, p. 5.

${ }^{11}$ RATTIGAN. The Browning Version, p. 11.

${ }^{12}$ RATTIGAN. The Browning Version, p. 42.
} 
Andrew. Taplow - I presume you are using a different text from mine -

Taplow. No, sir.

Andrew. That is strange, for the line as I have it reads: "hétis toiónd'ep'andrì kompázeis

lógon." However diligently I search I can discover no "bloody" - no "corpse" - no "you have slain". Simply "husband." -

Taplow. Yes, sir. That's right.

Andrew. Then why do you invent words that simply are not there?

Taplow. I thought they sounded better, sir. More exciting. After all she did kill her husban, sir. (With relish.) She's just been revealed with his dead body and Cassandra's weltering in gore -

Andrew. I am delighted at this evidence, Taplow, of your interest in the rather more lurid aspects of dramaturgy, but I feel I must remind you that you are supposed to be construing Greek, not collaborating with Aeschylus. (He leans back)

Taplow (greatly daring). Yes, but still, sir, translator's license, sir - I didn't see anything wrong - and after all it is a play and not just a bit of Greek construe.

Andrew (momentarily at a loss). I seem to detect a note of end of term in your remarks. I am not denying The Agamemnon is a play. It is perhaps the greatest play ever written $-{ }^{13}$

O diálogo continua com a pungente revelação de Andrew de que, quando jovem, fez uma tradução bastante livre do Agamêmnon, em dísticos rimados, apenas por seu próprio prazer e que sua intenção era comunicar a outros toda a emoção e excitação que a peça lhe transmitiu e ao terminá-la, achou-a muito bonita , "almost more beautiful than the original". Ao responder à pergunta de Taplow se ela foi publicada, Andrew diz que não, e também revela que ao tentar encontrar o manuscrito naquele dia, para empacotar suas coisas para a mudança, não o encontrou, e conclui "I fear it is lost - like so many other things. Lost for good." Antes de terminar esta lição, que revela tanto do caráter de Andrew e de suas emoções reprimidas, o professor pede a Taplow que releia o último verso por duas vezes, a última sem nenhuma expressão facial que acompanhe as palavras (o que reforça também sua postura reservada e contida). No momento em que Taplow começa a reler este verso tão significativo, ${ }^{14}$ "Pasmam-nos tua fala pela audácia, tal palavra ostentas sobre o homem”, Millie entra na sala informando que o Diretor Frobischer está chegando e passamos então para outra cena, sem a presença de Taplow. A rápida entrada de Millie, em momento tão particular, exemplifica como a construção da peça é cuidadosa, com uma precisão cirúrgica na composição das falas e mudanças de cenas, acompanhadas de ironias muito significativas. Em relação à cena anterior, um aspecto importante a considerar é, além de sua função reveladora das emoções de Andrew e da simpatia de Taplow que começa a se revelar, o fato de ela servir como elemento metateatral, por meio do qual podemos inferir o interesse de Rattigan em fazer uma releitura da tragédia de Ésquilo, atualizando seu poder dramático para o contexto do século XX.

Na cena com Frosbicher, o diretor faz alusão ao casal Gilbert, que irá morar na casa onde Andrew vive, mas sua visita traz uma informação desagradável para Andrew, que, no entanto, é recebida por ele de maneira estóica: a de que o conselho da escola não aprovou sua pensão, mesmo reconhecendo o bom serviço prestado por 18 anos à

\footnotetext{
${ }^{13}$ RATTIGAN. The Browning Version, p. 17.

${ }^{14}$ Cito a tradução para o português de J. Torrano, de 2004.
} 
escola. Ela traz também um pedido humilhante: que na cerimônia de despedida Andrew ceda sua prerrogativa de discursar por último para Fletcher, um jogador que fez muito pelo time de cricket da escola. Desta forma, a cerimônia terminaria com o longo aplauso que certamente os alunos dariam a Fletcher. Andrew concorda com a alteração, para evitar um anticlímax. Ambas as decisões serão duramente criticadas na cena seguinte por Millie. As reprimendas da esposa ao marido serão feitas enquanto ele folheia e sublinha passagens da tragédia Agamêmnon. Em uma das falas, Millie, reclamando da atitude cordata do marido, diz que ela teria tido outra reação frente ao "old phoney" diretor, no entanto, ela conclui de modo irônico: "But then of course, I'm not a man". ${ }^{15}$ A ironia está em que esta mulher tem, como Clitmnestra, um coração varonil (Ag., v. 11). Se, por um lado, ela reclama que Andrew deveria ter voz mais ativa e sustentá-la no casamento (o que o pequeno salário pago na nova escola certamente não possibilitará), por outro, ela tem um comportamento considerado masculino para aquele ambiente conservador: tomar as decisões e ter um amante.

Após a cena seguinte, em que o casal Gilbert é recebido pelos Crocker-Harris, Millie acrescenta um novo dissabor ao mais recente sofrido por Andrew - Peter, inadvertidamente, havia lhe informado que o diretor o chamou de "o Himmler do quinto ano". Millie compara a saída desonrosa do marido a uma hipotética despedida de Gilbert, recebendo flores, pensão e cumprimentos no estilo "Goodbye, Mr. Chips" (alusão ao premiado filme de 1939, que relata a boa influência de uma esposa sobre um professor e sua valorização e reconhecimento crescentes na escola). Esta cena, que deixa Andrew em estado deplorável - "You look dreadfull", são as palavras de Millie antes de sair -, prepara o encontro seguinte entre o professor, que continua tendo a mão seu Agamêmnon, e Taplow. O jovem vem se despedir do mestre, trazendo de presente um exemplar, comprado de segunda mão, do Agamêmnon na versão de Browning. A princípio Andrew não percebe que se trata de um presente e devolve o livro. À surpresa por receber um sinal de afeto segue-se a comoção ao ler a dedicatória, em grego. $\mathrm{O}$ espectador/leitor não é informado do texto escrito, apenas sente, como Taplow, certa ansiedade na medida em que o jovem teme ter errado na acentuação, já que Andrew é um mestre tão rigoroso. Mas o rigor é quebrado por uma emoção tão forte que Andrew pede a Taplow para buscar seu medicamento, enquanto ele se recompõe. Neste momento Frank retorna para o jantar com os Crocker-Harris. Envaidecido, Andrew mostra-lhe o presente e lê a dedicatória, informando que os versos vêm de um discurso de Agamêmnon a sua esposa, "God from afar looks graciously upon a gentle master". Trata-se dos versos 951-2 falados pelo chefe dos gregos logo após Clitemnestra persuadi-lo a entrar no palácio pisando sobre o tapete vermelho.

Quando Taplow sai de cena, Andrew teme ter-se mostrado um tanto tolo diante do aluno, no que é tranquilizado por Frank. No entanto, a entrada de Millie mudará radicalmente seu estado. Esta cena é o clímax da peça, pois neste momento, ao saber da dedicatória e ouvir do marido que ele preferiria ter este presente a qualquer outra coisa que ele pudesse imaginar, ela, rindo, diz a terrível frase "The artful little beast". Repreendida por Frank e solicitada a se explicar por Andrew, Millie diz que o presente não passa de "a few bobs' worth of appeasement.", pois Taplow, certamente temeroso que Millie contasse

${ }^{15}$ RATTIGAN. The Browning Version, p. 25. 
a Andrew que ela o viu imitando-o para Frank, naquela tarde, oferecera aquele presente como uma desculpa preventiva. Com a imediata saída de Andrew para seu quarto, Frank ("with a note of real repulsion in his voice") diz "Millie! My God" How could you?", ao que ela responde "Well, why not? Why should he be allowed his comforting little illusions? I' m not." Espantado com este pequeno gesto revelador de um caráter tão perverso, Frank tenta convencer Millie a corrigir o que fez, ao mesmo tempo que diz a ela que o relacionamento deles está acabado. Após chamá-lo de histérico (invertendo os papéis, já que em geral este é um adjetivo aplicado a mulheres), Millie não apenas tenta persuadi-lo a continuarem juntos como afirma - respondendo ao apelo de Frank para ter compaixão de um ser humano que foi tão ferido quanto pode ser um ser humano -, com um ar de desprezo: "Hurt? Andrew hurt? You can't hurt Andrew, he's dead!". ${ }^{16}$ Anteriormente, o diretor, ao conversar com Andrew, já havia feito uma alusão a "heroic battle" que "the most brilliant classical scholar we have ever had at the school" travava com "the soul-destroying lower fifth”. Na perspectiva de Frobisher, a razão dos problemas de Andrew é a classe e não a esposa, pois ele chega a chamar Andrew de "inválido sortudo" por ter uma enfermeira tão charmosa como Millie. ${ }^{17}$ Um comentário de Andrew feito posteriormente a Frank sobre sua reação ao presente de Taplow reforça seu estado de ser um "corpo" sem alma: "My hysteria over that book just now was no more than a sort of reflex action of the spirit. The muscular twitchings of a corpse." 18 Sua histeria é também um aspecto que o aproxima de Frank, se a observamos na mesma perspectiva de Millie, isto é, os dois homens têm este atributo feminino na peça.

Voltando à cena com Taplow, se considerarmos que emotividade de Andrew estava morta e havia sido ressuscitada pela ação do estudante (que pode ser visto, aqui, em papel semelhante ao de Orestes, resgatando a memória de seu pai), a atitude de Millie é a mesma de Clitmnestra, qual seja, destruir o marido no momento de sua glória máxima. Naturalmente, o reconhecimento pelos feitos guerreiros de Agamêmnon, simbolizado pela caminhada sobre o tapete vermelho, é de outra natureza que o prazer discreto e pessoal de Andrew, mas ambos são destruídos pelas respectivas esposas, seja pelos golpes certeiros no corpo do rei, após embaraçá-lo com a rede (Ag., v. 1380-1398), seja pelas palavras precisas "The artful little beast", que atingirão Andrew de tal modo que ele precisará de uma segunda dose de seu remédio para suportar o choque. Na cena seguinte, há uma longa conversa entre Frank e Andrew, que, recomposto em sua aparente insensibilidade, assegura não estar preocupado com o que Taplow ou Frank pensem sobre seu caráter. Andrew não apenas alega saber do caso entre Frank e Millie como também a defende, quando Frank a acusa de ser má, afirmando que sua esposa nunca mente. À insistência de Frank para Andrew deixar Millie, caso contrário ela irá matá-lo, Andrew responde "My dear Hunter, if that was indeed her purpose, you should know by now that she fulfilled it long ago." 19

\footnotetext{
${ }^{16}$ RATTIGAN. The Browning Version, p. 37.

${ }^{17}$ RATTIGAN. The Browning Version, p. 20-24.

${ }^{18}$ RATTIGAN. The Browning Version, p. 43.

${ }^{19}$ RATTIGAN. The Browning Version, p. 42.
} 
Naturalmente já estamos afastados, aqui, pela proximidade entre Frank e Andrew, da peça de Ésquilo, pois Egisto e Agamêmnon não são amigos. No entanto, esta proximidade masculina e a visão da mulher como elemento desordenador vai ao encontro do espírito da trilogia esquiliana. Lembremo-nos, por exemplo, do coro nas Coéforas (v. 585-650) dizendo que a audácia da mente do homem tem o paralelo no coração impudente das mulheres. Embora sejam ambos perigosos para os mortais, serão dados, apenas, exemplos ligados às mulheres. São lembrados os crimes de Altaia e Cila, que mataram, respectivamente, o filho e o pai. Em seguida à crítica ao casamento de Clitemnestra e sua traição (v. 626), o coro lembra o assassinato dos maridos pelas mulheres de Lemnos. Neste aspecto, a peça de Rattigan, apesar de espacial e temporalmente afastada da tragédia grega, mantém a mesma perspectiva em relação à figura feminina e à situação do marido dominado por uma mulher, como se percebe pelo que Andrew diz a Frank:

We are both of us interesting subjects for you microscope.... the love that we should have borne each other has turned to bitter hatred. That's all the problem is. Not an unusual one, I venture to think - nor nearly as tragic as you seem to imagine. Merely the problem of an unsatisfied wife and a henpecked husband. You'll find it all over the world. It is usually, I believe, a subject for farce. ${ }^{20}$

Se essa passagem pode dialogar com os versos finais de Agamêmnon, em que o coro diz que "Brada ousado como galo junto à galinha" (v. 1671), ela mostra com clareza que Rattigan sabia da impossibilidade de fazer, em meados do século XX, uma peça nos moldes da tragédia esquiliana, em que explicações psicológicas não se justificam. Trazendo para a contemporaneidade os personagens centrais, combinando e aproximando Frank e Andrew, Rattigan reforça o caráter trágico do protagonista, ainda que, como um todo, sua situação seja mais prosaica que singular; mas talvez esteja justamente aqui a genialidade do dramaturgo, em explorar a tragicidade do indivíduo preso nas redes da sociedade a que pertence. A peça termina com Andrew recebendo um telefonema do diretor, que faz algumas perguntas sobre o quadro de horário das turmas, elaborado por Andrew. Após esclarecer as dúvidas de seu superior, Andrew aproveita para dizer que mudou de ideia quanto à cerimônia de premiação e discursará por último, como é seu privilégio. Só ouvimos parte da conversa, que termina com a frase muito significativa de Andrew, que deve ser entendida também na perspectiva metateatral: "an anticlimax can be surprisingly effective". Suas últimas palavras são para Millie "Come along, my dear. We mustn't let our dinner get cold." Assim, mesmo que sua andréia como homem público seja respeitada, ele permanece ainda preso ao cotidiano de sua relação com Millie.

Nas duas adaptações da peça para o cinema os diretores seguiram o texto com bastante fidelidade. No entanto, ambos os filmes incluíram uma cena final que teve um toque edificante ao mostrar Andrew fazendo um discurso de mea culpa por ter falhado na nobre missão de "formar e cuidar da juventude" e recebendo o aplauso dos membros da escola, bem como se afastando da tirania da esposa. Mesmo que estas soluções tenham tornado a história menos dramática ou até mesmo menos trágica em certos momentos, certamente em favor de um filme mais ao gosto do público do main stream cinema, as

${ }^{20}$ RATTIGAN. The Browning Version, p. 42. 
adaptações são obras instigantes e cada uma tem momentos e soluções muito elaboradas na referência aos estudos clássicos. Elas mostram, também, pelas alterações na caracterização dos personagens, algumas mudanças significativas nos valores de seu tempo, ainda que entre ambas haja uma diferença de apenas 43 anos. Comum aos dois filmes é a utilização de cenas externas, seja nas dependências das escolas, com seus amplos gramados e austeros edifícios, seja nas cenas de partidas de cricket, jantares e celebrações acadêmicas, em que as togas pretas dão um ar solene à vida escolar. Certamente estes cenários minimizam a tensão da peça, concentrada inteiramente na sala dos Crocker-Harris.

O filme de 1951, como já disse, reuniu três nomes de primeira grandeza - Asquith, Redgrave e Rattigan. No entanto, os atores coadjuvantes, Nigel Patrick (Frank), Jean Kent (Millie) e Brian Smith (Taplow) têm performances excelentes que, combinadas à irreparável atuação de Redgrave, são um dos elementos que fazem desta uma obra de arte do cinema clássico, o que se confirma pelos prêmios que recebeu. $O$ filme pode ser apreciado, independentemente do conhecimento que o espectador tenha da tradição grega e de suas referências às peças de Rattigan ou de Ésquilo, em parte pelo cuidadoso estudo do comportamento humano e construção de personagens. No entanto, as sutis e sofisticadas alusões ao texto esquiliano devem ser explicitadas para observarmos em que consistiu a transposição das duas peças (de Ésquilo e de Rattigan) para a tela. Chamarei a atenção para três elementos que, a meu ver, se sobressaem no filme.

Começo destacando a presença de uma passagem do primeiro estásimo do Agamêmnon, mais precisamente dos versos 414-19, no quadro negro da sala de aula de Andrew, cenário que serve para duas cenas importantes, uma entre Andrew e seus alunos, outra entre ele e o novo professor de grego. A passagem aparece, ainda que incompleta, sobreposta a imagens de Andrew e sua esposa nas capas das edições inglesa e brasileira do DVD, o que enfatiza sua importância. Os versos citados foram muito bem escolhidos, pois falam da presença incômoda para Menelau das belas estátuas, após a partida de sua mulher, Helena. A palavra inical, póthos significa justamente desejo ou saudade de algo que foi perdido.
póthoi d'huperpontías
phásma dóksei dómon anássein
eumórphon dè kolossôn
ékhthetai kháris andrí
ommáton d'en akheníais
érrei pãs' Aphrodíta. ${ }^{21}$

Estes versos escritos no quadro negro compõem o cenário da última aula de Andrew, no qual se destaca, também, uma reprodução de um friso de Nike amarrando a sandália (cujo original está no Museu da Acrópole). A amargura e rigidez do professor ecoam a amargura de Menelau, transformada aqui em aspereza com os alunos. Muito significativo observar que na classe, antes de Andrew chegar, os jovens se perguntavam qual seria a

\footnotetext{
${ }^{21}$ ÉSQUILO. Ag., 414-419: "Por desejo de mulher além-mar/ espectro parecerá senhor do palácio./ Nas belas formas de estátuas/a graça é odiosa ao marido,/ na vacuidade do olhar/ esvai-se toda Afrodite". Para uma análise desta passagem no contexto da peça, e da proximidade entre Helena e Clitemnestra, cf. COELHO. Imagens de Helena, p. 162-164.
} 
doença que o afastara da escola e quando Taplow informa que é um problema de coração, um deles diz ser uma ironia, já que se podia dizer justamente que Crock era um homem sem coração. A segunda cena para o qual os versos servem de cenário ocorre quando Andrew se dirige a sua sala para desocupá-la. Ao retirar seus livros ele encontra uma pasta com a sua tradução do Agamêmnon, a respeito da qual havia falado com Taplow e que considerava perdida "como tantas outras coisas". Neste momento, aparece o novo professor de grego. Andrew tem uma longa conversa com ele, lamentando não ter transmitido a alegria que sentia com a literatura grega e ter até perdido a capacidade de ser objeto de atenção dos alunos, ainda que fosse apenas porque suas maneiras afetadas despertassem o riso dos jovens. Sente ter falhado na sua profissão, dizendo que certamente uma doença da sua alma, não de seu corpo, fez com que merecesse o apelido de Himmler, concluindo o desabafo com a frase: "talvez este seja meu epitáfio". Se o contexto da guerra é estrutural na tragédia de Agamêmnon e o papel do irmão de Menelau como comandante maior do exército grego realça sua queda e derrota pelas mãos de uma mulher, na peça de Rattigan e neste filme o apelido de "Himmler of the lower fifth" ecoa o contexto da Segunda Guerra, mas como disse, dentro do ambiente privado de uma escola ou casa (na versão cinematográfica de 1994, Himmler é substituído por Hitler, certamente para compreensão do público, para quem o nome do comandante da SS já não tem significado evidente). ${ }^{22}$

O segundo elemento que encontramos no filme é a inclusão de uma cena em que Taplow, ao visitar Andrew, vê a pasta com a tradução de Agamêmnon, e que ele, em outro momento, pegará furtivamente. Na última cena do filme, após o discurso de Andrew e sua saída honrosa, sob os aplausos de toda a escola, Taplow o encontra e lhe dá a pasta, após ter lido seu conteúdo, e diz: "I think it's rather good. It's a jolly sight better than old Browning's anyway...I found it quite exiting. It's like a play. I mean, a real play, I mean a modern play. It is really worth finishing." Se, por um lado, esta cena reforça a redenção de Andrew diante de seus alunos e de si mesmo, por outro, pensada do ponto de vista metateatral, ela justificaria esteticamente não apenas a peça de Rattigan, mas sua própria adaptação para o cinema (não esqueçamos que é Rattigan a escrever o roteiro). Ligado a este segundo elemento, temos o terceiro. A razão de uma última visita de Taplow à casa de Andrew é levar a Millie um pacote de Frank. Estamos no final do filme e Andrew decidiu não acompanhar Millie a Bradford, ficando sozinho até a época de sua mudança para a nova escola. Millie está pronta para partir, tentando telefonar para Frank, ao que parece para convencê-lo a se reencontrar com ela em Bradford e reatar o romance. Ao receber de Taplow o pacote (contendo uma cigarreira de metal, presente seu ao amante), Millie prostra-se em uma poltrona, deixando a cigarreira cair no chão. Taplow sai rapidamente, pegando, curioso, a pasta de Andrew que estava em uma lixeira. Andrew, passando pela sala, apanha a cigarreira, colocando-a ao lado de Millie, sem

\footnotetext{
${ }^{22}$ A justificação para a escolha deste nome é o papel disciplinador e rígido do velho professor de grego, mas sem dúvida há um enorme exagero e distorção de natureza, é claro, que assuta o próprio Andrew, dada a figura sombria do chefe da Gestapo. Quem chamou minha atenção para o uso do nome de Hitler foi o acadêmico Frederico Gorski, durante o curso Cinema, Literatura e Filosofia: tragédia e comédia gregas na tela, ministrado no segundo semestre de 2003, na Universidade do Estado de Santa Catarina.
} 
falar nada. Em seguida Millie guarda o objeto na bolsa e parte, também sem falar nada com o marido, que já está à mesa corrigindo seu discurso de despedida. Creio que esta cena pode ser vista como uma releitura da volta de Orestes para matar a mãe - a cigarreira de metal teria o mesmo papel destruidor que a espada no peito da mãe. Restaurar a memória e a honra do pai é o ato seguinte, quando Taplow recupera a pasta com a tradução de Andrew, a qual lhe será entregue na última cena do filme. Desta forma, estas opções na adaptação cinematográfica, mesmo que alterem certo tom mais sombrio da peça de Rattigan, dialogam de maneira interessante com a peça de Ésquilo e tornam o filme uma versão diferente, porém não menos convidativa para refletirmos sobre a razão do velho mito se transformar e se manter vivo nos anos 1950 do século XX por meio de uma arte popular como é o cinema (desnecessário dizer que o teatro grego antigo também pode ser visto como arte popular, ainda que a tradição o tenha elitizado, já que, aristotelicamente, o conhecemos, principalmente, por meio dos textos e encenações em espaços pouco acessíveis).

Quanto à versão cinematográfica de 1994, destacam-se os fatos de não ter a sutileza da versão de 1951 e de ter dado explicações para o comportamento de Millie, alterando de maneira significativa a reação de antipatia que a personagem despertava antes. Aliás, o nome de Millie é também alterado e a mulher de Andrew se chama, neste filme, Laura. Albert Finney e Greta Scacchi interpretam o casal Croker-Harris; para o papel de Frank foi escolhido o ator americano Matthew Modine, e Taplow e Gilbert foram interpretados por Ben Silverstone e Julian Sands, respectivamente - atuações todas excelentes. Como as escolas de elite inglesas mantêm ainda muitas tradições, principalmente nos cerimoniais, o filme não parece desatualizado. Algumas inovações quanto à presença de estrangeiros nas classes ou a modernização dos currículos foram introduzidas, mas o que se faz notar mais é o que muda na personagem feminina. A amargura da esposa de Andrew não foi minimizada e Greta Scacchi faz muito bem as cenas em que, com algumas palavras e um olhar, "apunhala" o marido. No entanto, seu comportamento, se não é justificado, é explicado por uma opção infeliz (dela e de Andrew). Além disso, diferentemente de Millie, ela demonstra ainda afeto por Andrew, chegando a assistir ao seu discurso de despedida e cumprimentá-lo com deferência antes de se separar dele. A relação entre os homens, apesar de tudo, ainda é pautada pela lealdade e companheirismo, enquanto a figura feminina se destaca como elemento perturbador. Ainda que Andrew diga a Frank, no momento em que este o procura para sugerir uma separação, "Don't take sides", ele dará um basta em seu casamento torturante em parte alertado pela atitude solidária do colega professor.

Se o filme de Mike Figgis não tem algumas das sutilezas daquele de Asquith, ele não deixa de ter cenas memoráveis. Uma delas é a performance de Albert Finney ao ler, como "presente" de despedida para sua classe, um trecho de Agamêmnon, que é justamente a parte em que, no filme de Asquith, Taplow começará a ler, a partir do verso 1372 (mas que nós não podemos ouvir, pois naquele filme havia um corte para uma cena de Millie e Frank no jardim). Esta cena ocorre bem no começo do filme, o que já produz, desde o início, uma simpatia do espectador por Andrew, cuja leitura, acompanhada por um fundo musical muito apropriado, impressiona de tal modo os alunos (e o espectador), especialmente Taplow, que este, posteriormente, dirá ao mestre que gostaria de traduzir 
um texto grego com a mesma eficácia, a fim de transmitir uma emoção tão vívida como aquela que o professor transmitiu em classe. Na leitura de Andrew ele fizera um comentário sobre a existência de esposas que destruíram maridos, notando que mesmo que Ésquilo não as tivesse conhecido pessoalmente, elas existiam. Essa afirmação, a meu ver, predispõe o espectador a reagir negativamente aos comentários destrutivos de Laura, que culminam com a afirmação, em público, no momento em que Andrew está cercado pelos colegas, de que o presente de Taplow não passava de um suborno. A carga emocional desta cena só é comparável à da cena inicial, em que Andrew lera para os alunos a descrição do assassinato de Agamêmnon, enredado pela astúcia da esposa. Se o final desta versão - Laura tendo, como as Erínias, sua fúria aplacada pelas palavras persuasivas de Andrew - é mais conciliador que trágico, o filme não cai no melodrama, em parte pela atuação contida dos personagens, mesmo na cena final em que Andrew caminha pelo tapete vermelho, sob um olhar, agora purificado pelas lágrimas, de uma Clitemnestra benevolente. Assim, apesar de certas inversões, e talvez por isso mesmo, o filme nos estimula a dialogar com os textos de Rattigan, Browning e Ésquilo.

Nesse contexto, chamo a atenção para um dos momentos em que no filme de Figgis Andrew fazia a leitura do Agamêmnon. Corrigindo a entonação inexpressiva de um dos alunos a quem havia pedido para ler e traduzir os versos relativos à cena da morte do rei, o professor diz que é necessário ter imaginação para poder ler adequadamente: “Imagination!". Imaginação parece ser um elemento-chave quando pensamos na releitura, adaptação e transposição de grandes obras poéticas, e é o que vemos nas obras destes autores contemporâneos reescrevendo e encenando os clássicos no do século do cinema, época em que o mito do amor também entrou em cena.

\section{A B S TR A C T}

In this paper an analysis is made of some aspects of Terence Rattigan's play The Browning Version (1948), in which Rattigan made reference to the famous translation of Aeschylus's Agamemnon by Robert Browning, in 1877. I also analyze two homonymous films The Browning Version (Nunca te amei), directed by Anthony Asquith, in 1951, and by Mike Figgis, in 1994, both based in Rattigan's play.

\section{KEYWORDS}

Greek tragedy, The Browning version, cinema

\section{REFERÊNCIAS}

ASQUITH, Anthony (direção) e RATTIGAN, Terrence (roteiro). The Browning Version Inglaterra, Distribuição: Universal Pictures, produção: Javelin Films, 1951, P\&B. 90 min. BANDEIRA, Manuel. Crônicas da Província do Brasil. São Paulo: CosacNaify, 2006, 320 p. BENITEZ, Eugene. On Literal Translation: Robert Browning and the Agamemnon. Philosophy and Literature 28, p. 259-268, 2004. 
COElHO, Maria C. M. N. Imagens de Helena. Clássica, 13/14, p. 159-172, 2000/2001. COELHO, Maria C. M. N. Helena de Tróia no cinema: metamorfoses do mito. Anais do 2ํo Simpósio de Estudos Clássicos da USP. São Paulo: Humanitas, 2006. p. 131-159.

DARLOW, Michael; HODSON, Gilian. Terence Rattigan: The Man and his Work. London: Quartet Books, 1979. 360 p.

ÉSQUILO. Agamêmnon. Trad. Jaa Torrano. São Paulo: Iluminuras, 2004. 223 p.

FIGGIS, Mike (direção); HARWOOD, Ronald (roteiro). The Browning Version. Inglaterra. Distribuição: Paramount, Produção Percy films, 1994, Colorido, 97 min.

GOLDER, Herber "Geek" Tragedy? - Or, Why I'd Rather go to the Movies. Arion 1, 4, p. 175-209, 1996.

PRINS, Yopie OTOTOTOI: Virginia Woolf and the Naked Cry of Cassandra In: MACINTOSH, Fiona et al. Agamemnon in Performance 458 BC-AD 2004. Oxford: Oxford U. P., 2005. p. 163-187.

RATTIGAN, Terrence. The Browning Version. In: Playbill: The Browning Version and Harlequinade. Introdução de Dan Rebellato. London: Nick Hern Books, 1994. 125 p. TAPLIN, Oliver. The Harrison Version. In: MACINTOSH, Fiona et al. Agamemnon in Performance. 458 BC.-AD 2004. Oxford: Oxford U. P., 2005. p. 235-251. 